\title{
Evaluation of adherence to pharmacological treatment
}

\author{
William Henrique da Silva', Débora Santos Dantas', Baldoíno Sonildo da Nóbrega², \\ Maria do Socorro Ramos de Queiroz ${ }^{1}$ Harley da Silva Alves ${ }^{\circledR 1^{*}}$
}

\begin{abstract}
${ }^{1}$ Department of Pharmacy/Post-Graduation Program in Pharmaceutical Sciences, State University of Paraiba, Campina Grande, Paraiba, Brazil, ${ }^{2}$ Federal Institute of Science and Technology of Paraíba, Cajazeiras, Paraiba, Brazil
\end{abstract}

\begin{abstract}
The adherence to therapy associated with the socio-demographic variables and the habits of patients with hypertension and/or diabetes mellitus were investigated in this study. The registration forms of 105 patients in the Hiperdia program in the municipality of Campina Grande-PB were used as a data collection instrument, applying the Morisky-Green test (MGT) and Batalla test (BT) to assess compliance treatment. For the MGT, there was a prevalence of non-adherent individuals (76.2\%) and the type of predominant behavior was unintentional. The internal consistency of the responses obtained through the MGT presented good reliability, according to the value of 0.69 obtained by Cronbach's alpha. For the BT, there was a predominance of adherence $(68.6 \%)$ and the alpha value was 0.80 , showing a high reliability level. It was found that a diet lacking in salt is a strong impact variable for determining the adherence to the BT. Given the representativity of the tests, there is a need to amend the interferences that facilitate the low adherence to drug treatment. The results of this study can be used to construct strategies that will address these difficulties and optimize the adherence level and quality of life of patients.
\end{abstract}

Keywords: Therapeutic adherence. Hypertension. Diabetes mellitus.

\section{INTRODUCTION}

The prevalence of hypertension and diabetes mellitus (DM) has increased worldwide, especially in lowand middle-income countries. In a report, the World Health Organization (WHO, 2012) highlighted the growing problem of the increase in non-communicable diseases and showed that about $30 \%$ of the world population presents hypertension and $10 \%$ presents DM.

In Brazil, hypertension presents itself as a serious public health problem due to its high prevalence, affecting between $15 \%$ and $20 \%$ of the adult population and more than $50 \%$ of the elderly (Carvalho Filha, Nogueira, Viana, 2011; Strelec, Pierin, Mion, 2011). As most of its course is asymptomatic, its diagnosis and treatment are often neglected; in addition, therapeutic adherence tends to be low, which results in an inadequate control of hypertension (Ministry of Health of Brazil, 2006).

$\mathrm{DM}$ is one of the major public health diseases in Brazil. Its incidence and prevalence are increasing

\footnotetext{
*Correspondence: H. S. Alves. Departamento de Farmácia/Programa de PósGraduação em Ciências Farmacêuticas, Universidade Estadual da Paraíba. Av. das Baraúnas, 351, Bairro Universitário, Campina Grande-PB, Brasil. Tel.: +55 (83) 3315-3317. E-mail: harley.alves@hotmail.com
}

in epidemic proportions, reaching a $7.6 \%$ prevalence in a national study carried out in various capital cities. It is associated with complications that compromise productivity, quality of life, and survival of individuals (Barros, Rocha, Helena, 2008).

The Ministry of Health (MS) of Brazil has created numerous programs to control diseases with the greatest impact on the population. In the case of hypertension and DM, the MS has implemented the National Program of Hypertension and Diabetes Mellitus - Hiperdia. This program promotes the reorientation of pharmaceutical assistance by providing a continuous and free supply of medicine, in addition to monitoring the clinical conditions of each user (Carvalho et al., 2012; Ministry of Health of Brazil, 2001).

In this approach, an aspect of the treatment of these diseases has been given great importance: adherence to treatment. Accession corresponds to the agreement among the medical prescription and the patient's conduct, as it is a predominant reason for concern in the control of hypertension and DM. However, a large portion of hypertensive and diabetic people do not use the drugs properly or change their routines and physical activity to control such diseases, which can sometimes manifest with 
or without symptoms (Girotto, 2008; Figueiredo et al., 2001)

In chronic diseases, whose treatment demands the continuous use of medicines, patient adherence to the prescribed drug regimen is essential (Dewulf et al., 2006).

Lack of treatment compliance by patients with hypertension and/or DM is common and associated with many factors, such as difficulty following the treatment, financial difficulties, adverse effects of drugs, difficulty accessing healthcare, the inadequacy of the doctor-patient relationship, as well as the very characteristics of the disease, which usually presents itself as asymptomatic in the first 15 to 20 years, in addition to its chronicity (Girotto, 2008; Busnello et al., 2001).

This study aimed to investigate the adherence to therapy associated with sociodemographic data and the lifestyle of patients with hypertension and/or DM.

\section{METHODS}

\section{Study design}

This is descriptive research with a quantitative approach of the documental type. It was carried out from January to June 2015 in the Family Health Strategy (FHS) Galante I and II, municipality of Campina Grande, state of Paraíba, Brazil.

\section{Study population and methodology used}

We selected 105 participants in accordance with the criteria for inclusion and exclusion.

All patients of the local Hiperdia program who agreed to participate in the survey were included by signing the Terms of Consent (TFCC). Exclusion criteria were: patients aged $<18$ years, illiteracy, and cognitive deficits.

To assess adherence to the pharmacological treatment, two standardized tests were used: the MoriskyGreen Test (MGT) and the Batalla Test (BT). The two tests are standardized, characterized as indirect evaluation instruments through self-report. The MGT is a scale composed of four questions, as shown in Table I. According to the original MGT, respondents are classified in only two groups: adherents or non-adherents. Adherents are considered individuals who answer all questions correctly and earn four points, and non-adherents are those who obtain three points or less (Morisky, Green, Levine, 1986; Strelec, Pierin, Mion, 2003).

This research, in addition to the original classification adopted by the MGT, has applied a proposal presented by Medeiros (2006), who suggested the adoption of

\begin{tabular}{|l|c|l|l|}
\hline \multicolumn{1}{|c|}{ Questions } & Type of behavior & \multicolumn{2}{|c|}{ Score } \\
\hline $\begin{array}{l}\text { 1st "Did you ever forget } \\
\text { to take your medicine?" }\end{array}$ & Unintentional & Yes (0) & No (1) \\
\hline $\begin{array}{l}\text { 2nd "Are you } \\
\text { sometimes careless } \\
\text { about the time of taking } \\
\text { your medicine?" }\end{array}$ & Unintentional & Yes (0) & No (1) \\
\hline $\begin{array}{l}\text { 3rd "When you feel } \\
\text { good, ever, do you stop } \\
\text { taking your medicine?" }\end{array}$ & Intentional & Yes (0) & No (1) \\
\hline $\begin{array}{l}\text { 4th "When you feel bad, } \\
\text { with the remedy, } \\
\text { sometimes do you stop } \\
\text { taking it?" }\end{array}$ & Intentional & Yes (0) & No (1) \\
\hline
\end{tabular}

FIGURE 1 - Questions that make up the MGT and classification regarding the intention of the types of low adherence behavior (Adapted from Morisky, Green, Levine, 1986).

a reclassification into three subgroups to characterize adherence to drug treatment based on the number of points obtained on the MGT: low $=0$ or 1 point; moderate $=2$ or 3 points; high adherence $=4$ points, to better assess the individual components of the MGT.

The BT, which measures adherence through the participants' knowledge about their disease, is composed of three questions (Carvalho, Nogueira, Viana, 2011). In this study, in accordance with the BT, the questions were asked as follows: 1st: "Are hypertension and DM diseases for life?" 2nd: "Can you control the hypertension and the DM with diet and/or medication?" 3rd: "Cite two or more organs that may suffer injuries by hypertension or DM." The questions were directed in relation to the type of disease presented by the user. The BT considers patients' to be adherent if they answer the three questions correctly.

\section{Data collection}

To evaluate the sociodemographic and economic variables (age, gender, occupation, retired, monthly family income, education, marital status, number of persons residing in the house) and life habits (non-communicable chronic diseases [NCCD], heredity, alcoholism, smoking, diet lacking in salt, exercising), the records of registration and tracking of the patients of the program Hiperdia were analyzed.

\section{Data analysis}

Data were typed and handled in Microsoft Excel (2010) and SPSS 17.0 (SPSS, Inc. 2008). Quantitative analysis of the data was made by calculating frequency distributions and percentages. For decision making in 
relation to data, we sought to test the internal homogeneity of the variables and independence among them using the Chi square $\left(\chi^{2}\right)$ statistical test or Fisher Exact Test. The results were considered significant when the significance level (p) was less than 0.01 .

As a statistical tool to quantify the reliability of the questionnaire the Cronbach's alpha test was used. The minimum acceptable value for alpha is 0.70 , on a scale from 0 to 1 (Streiner, 2003).

\section{Ethical aspects}

The project was approved by the Ethics Research Committee in research involving humans at the State University of Paraíba, through opinion No. 34912814.0.0000.5187.

\section{RESULTS}

According to Table I, we verified that of the 105 patients interviewed, most of them were female $(74.3 \%)$, adults $(53.3 \%)$, ranged in age from 26 to 83 years with an average of $58.27 \pm 12.52$ years, married $(68.6 \%)$, pensioners $(53.3 \%)$, and had a monthly family income in the range of 1 to 3 times the minimum wage $(86.7 \%)$. The most common occupations were farmer $(50.5 \%)$ and housewife $(27.6 \%)$. The most prevalent level of education was incomplete primary education $(51.4 \%)$. With respect to the number of human residents per household, we obtained an average of $3.43( \pm 1.53)$. Regarding diseases, hypertension, and/or DM, it was observed that 81 participants $(77.1 \%)$ had only hypertension, $4(3.8 \%)$ had only diabetics, and $20(19 \%)$ had both morbidities.

Research on smoking and alcoholism habits of the patients showed that there was a prevalence of participants who reported not to be smokers $(93.3 \%)$ or intake alcoholic beverages $(89.5 \%)$. We identified that a predominance of participants, a total of $62(59.0 \%)$, possessed the hereditary factor for developing hypertension and/or DM. Regular physical exercise and a diet lacking in salt $(\mathrm{NaCl})$ were also analyzed. We identified that 69 (65.7\%) of the participants are sedentary and do not have a habit of regular physical exercise. As to the implementation of the recommendation of a diet lacking in salt, this eating plan was observed in $58(55.2 \%)$ patients (Table I).

The Chi Square test of adherence (Table I) presented a $\mathrm{p}$-value greater than 0.01 for the salt diet variable, suggesting that there are no significant

TABLE I - Distribution of sociodemographic and economic variables of Hiperdia users (Applying the Chi Square analysis of variables adherence).

\begin{tabular}{|c|c|c|c|c|c|}
\hline Variables & Quantities & $\%$ & Test & p-value & Analysis \\
\hline \multicolumn{6}{|l|}{$\overline{\text { Age (years) }}$} \\
\hline Between 20 and 59 & 56 & $53.3 \%$ & $\chi^{2}$ & 0.495 & NS1 \\
\hline$\geq 60$ & 49 & $46.7 \%$ & & & \\
\hline \multicolumn{6}{|l|}{ Gender } \\
\hline Masculine & 27 & $25.7 \%$ & $\chi^{2}$ & 0.001 & $\mathrm{AS} 2$ \\
\hline Feminine & 78 & $74.3 \%$ & & & \\
\hline \multicolumn{6}{|l|}{ Occupation/Profession } \\
\hline Farmer & 53 & $50.5 \%$ & $\chi^{2}$ & - & - \\
\hline Housewife & 29 & $27.6 \%$ & & & \\
\hline Other & 23 & $21.9 \%$ & & & \\
\hline \multicolumn{6}{|l|}{ Retired } \\
\hline Yes & 56 & $53.3 \%$ & $\chi^{2}$ & 0.467 & NS \\
\hline No & 49 & $46.7 \%$ & & & \\
\hline \multicolumn{6}{|c|}{ Monthly household income (n. minimum wages) } \\
\hline Less than 1 minimum wage & 9 & $8.6 \%$ & $\chi^{2}$ & 0.001 & AS \\
\hline Between 1 and 3 minimum wages & 91 & $86.7 \%$ & & & \\
\hline More than 3 minimum wages & 5 & $4.7 \%$ & & & \\
\hline \multicolumn{6}{|l|}{ Education } \\
\hline Incomplete primary education & 54 & $51.4 \%$ & $\chi^{2}$ & 0.001 & AS \\
\hline Complete primary education & 29 & $27.6 \%$ & & & \\
\hline Incomplete high school & 9 & $8.6 \%$ & & & \\
\hline Complete high school & 13 & $12.4 \%$ & & & \\
\hline
\end{tabular}


TABLE I - Distribution of sociodemographic and economic variables of Hiperdia users (Applying the Chi Square analysis of variables adherence) (cont.)

\begin{tabular}{|c|c|c|c|c|c|}
\hline Variables & Quantities & $\%$ & Test & p-value & Analysis \\
\hline \multicolumn{6}{|l|}{$\overline{\text { Marital Status }}$} \\
\hline Single & 15 & $14.3 \%$ & $\chi^{2}$ & 0.0001 & AS \\
\hline Married & 72 & $68.6 \%$ & & & \\
\hline Widower & 10 & $9.5 \%$ & & & \\
\hline Divorced/Separated & 6 & $5.7 \%$ & & & \\
\hline Other & 2 & $1.9 \%$ & & & \\
\hline Number of persons residing in the house & & & - & - & - \\
\hline $1(1)$ & 6 & $5.7 \%$ & $\chi^{2}$ & 0.0001 & AS \\
\hline 2 to $3(2)$ & 54 & $51.4 \%$ & & & \\
\hline 4 to $5(3)$ & 38 & $38.0 \%$ & & & \\
\hline 6 to $8(4)$ & 7 & $6.7 \%$ & & & \\
\hline \multicolumn{6}{|l|}{ Non-communicable chronic diseases } \\
\hline Hypertension & 81 & $77.1 \%$ & $\chi^{2}$ & 0.0001 & AS \\
\hline Diabetes Mellitus & 4 & $3.8 \%$ & & & \\
\hline Hypertension and Diabetes Mellitus & 20 & $19.0 \%$ & & & \\
\hline \multicolumn{6}{|l|}{ Heredity } \\
\hline Yes & 62 & $59.0 \%$ & $\chi^{2}$ & 0.064 & NS \\
\hline No & 43 & $41.0 \%$ & & & \\
\hline \multicolumn{6}{|l|}{ Alcoholism } \\
\hline Yes & 11 & $10.5 \%$ & $\chi^{2}$ & 0.0001 & AS \\
\hline No & 94 & $89.5 \%$ & & & \\
\hline \multicolumn{6}{|l|}{ Smoking } \\
\hline Yes & 7 & $6.7 \%$ & $\chi^{2}$ & 0.0001 & AS \\
\hline No & 98 & $93.3 \%$ & & & \\
\hline \multicolumn{6}{|l|}{ Physical exercise } \\
\hline Yes & 36 & $34.3 \%$ & $\chi^{2}$ & 0.001 & AS \\
\hline No & 69 & $65.7 \%$ & & & \\
\hline \multicolumn{6}{|l|}{ Salt diet } \\
\hline Yes & 58 & $55.2 \%$ & $\chi^{2}$ & 0.283 & NS \\
\hline No & 47 & $44.8 \%$ & & & \\
\hline
\end{tabular}

1 NS: Non-Asymptotic Test, where $p>0.01 .2$ AS: Asymptotic Test, where $p>0.01$.

differences between categories; this is concerning, given that only $55.2 \%$ of participants adopted a diet lacking in salt, while all patients suffering of hypertension and/or DM require a high level of accession with respect to this recommendation.

Using the MGT original classification criterion, only 24 participants were considered to be adherent.

Considering the proposal of Medeiros (2006) to reclassify the interviewed patients into three groups by the MGT, 25 patients $(23.8 \%)$ were classified as a group with a high level of accession, 65 (61.9\%) as medium accession, and only $15(14.3 \%)$ participants fell within the range of low accession.

When observing the patients' answers in detail to the four questions of the MGT, the most negative responses referred to Questions 1 and 2, reaching values of 59.0\% and $41.0 \%$, respectively, according to Figure 2.

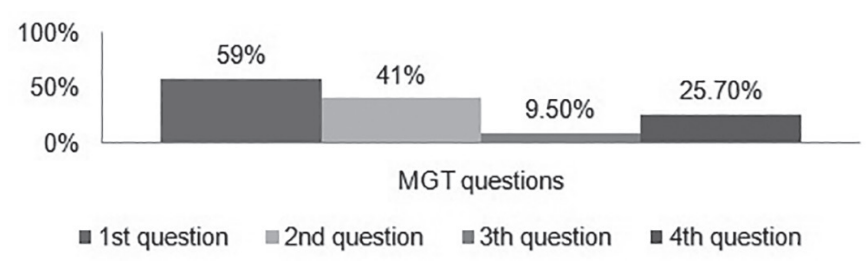

FIGURE 2 - Individual examination of the MGT (Morisky-Green test) questions, showing the percentage of negative responses obtained in the interview.

The internal consistency of the responses obtained through the MGT showed that this measuring instrument 
showed good reliability, according to the Cronbach's alpha value of 0.69 .

As for the results of the BT, which addresses the respondents' knowledge level about their conditions, it was found that $72(68.6 \%)$ were considered to be adherent, while only 33 (31.4\%) were classified as nonadherent.

According to the Cronbach's alpha value (0.80), the results showed high reliability.

In the analysis of sociodemographic variables (age, gender, occupation/ profession, retired, monthly income, education, marital status, and number of people residing in the house) and lifestyle (NCCD, heredity, alcohol consumption, smoking, exercise, and salt diet) as possible interfering factors in adherence to drug treatment, according to MGT, there was no significant association between them and adherence ( $\mathrm{p}>0.01)$, this is, the variables are independent, as shown in Table II.

However, in the analysis of the variables as possible confounders in adherence to drug treatment, according to
BT (Table III), the variable "Salt Diet" presented a p-value lower than 0.01, suggesting an association between the variables. Analyzing the contingency coefficient, a correlation of $23.2 \%$ was shown between the variables, which is considered low.

Regarding the third question of BT, which seeks to find out if the user knows the organs that can be affected by uncontrolled hypertension and/or DM, this study found that the most cited organs were: heart, kidneys, brain, and eyes.

\section{DISCUSSION}

The analysis of socioeconomic characteristics features individuals as being predominantly low-income and socially excluded, and that the public health services in primary health care are directed to this part of society; this corroborates with Assis, Villa and Nascimento (2003) as well as demonstrates that the population served by the

TABLE II - Distribution of sociodemographic and economic variables of Hiperdia users to analyze the association between the variables and adherence to MGT

\begin{tabular}{|c|c|c|c|c|}
\hline Variables & Adherence-MGT & $\%$ & p-value & Test \\
\hline \multicolumn{5}{|l|}{ Age (years) } \\
\hline Between 20 and 59 & 15 & $25.0 \%$ & 0.373 & $\chi^{2}$ \\
\hline$\geq 60$ & 10 & $20.4 \%$ & & \\
\hline \multicolumn{5}{|l|}{ Gender } \\
\hline Masculine & 9 & $34.6 \%$ & 0.1 & $\chi^{2}$ \\
\hline Feminine & 16 & $19.0 \%$ & & \\
\hline \multicolumn{5}{|l|}{ Occupation/Profession } \\
\hline Farmer & - & - & - & - \\
\hline Housewife & - & - & & \\
\hline Other & - & - & & \\
\hline \multicolumn{5}{|l|}{ Retired } \\
\hline Yes & 11 & $19.6 \%$ & 0.272 & $\chi^{2}$ \\
\hline No & 14 & $26.5 \%$ & & \\
\hline \multicolumn{5}{|c|}{ Monthly household income (n. minimum wages) } \\
\hline Less than 1 minimum wage & 4 & $36.4 \%$ & 0.235 & Fisher \\
\hline Between 1 and 3 minimum wages & 19 & $20.2 \%$ & & \\
\hline More than 3 minimum wages & 2 & $40.0 \%$ & & \\
\hline \multicolumn{5}{|l|}{ Education } \\
\hline Incomplete primary education & 16 & $27.3 \%$ & 0.276 & Fisher \\
\hline Complete primary education & 3 & $10.7 \%$ & & \\
\hline Incomplete high school & 3 & $33.3 \%$ & & \\
\hline Complete high school & 3 & $23.1 \%$ & & \\
\hline \multicolumn{5}{|l|}{ Marital Status } \\
\hline Single & 0 & $0.0 \%$ & 0.08 & Fisher \\
\hline Married & 19 & $25.4 \%$ & & \\
\hline Widower & 4 & $36.4 \%$ & & \\
\hline Divorced/Separated & 2 & $33.3 \%$ & & \\
\hline Other & 0 & $0.0 \%$ & & \\
\hline
\end{tabular}


TABLE II - Distribution of sociodemographic and economic variables of Hiperdia users to analyze the association between the variables and adherence to MGT (cont.)

\begin{tabular}{|c|c|c|c|c|}
\hline Variables & Adherence-MGT & $\%$ & p-value & Test \\
\hline \multicolumn{5}{|l|}{ Number of persons residing in the house } \\
\hline $1(1)$ & 1 & $16.7 \%$ & 0.54 & Fisher \\
\hline 2 to $3(2)$ & 14 & $24.5 \%$ & & \\
\hline 4 to $5(3)$ & 7 & $17.9 \%$ & & \\
\hline 6 to $8(4)$ & 3 & $42.9 \%$ & & \\
\hline \multicolumn{5}{|l|}{ Non-communicable chronic diseases } \\
\hline Hypertension & 16 & $18.5 \%$ & 0.105 & Fisher \\
\hline Diabetes Mellitus & 1 & $25.0 \%$ & & \\
\hline Hypertension and Diabetes Mellitus & 8 & $40.0 \%$ & & \\
\hline \multicolumn{5}{|l|}{ Heredity } \\
\hline Yes & 13 & $19.4 \%$ & 0.305 & $\chi^{2}$ \\
\hline No & 12 & $27.9 \%$ & & \\
\hline \multicolumn{5}{|l|}{ Alcoholism } \\
\hline Yes & 1 & $9.1 \%$ & 0.45 & Fisher \\
\hline No & 24 & $24.5 \%$ & & \\
\hline \multicolumn{5}{|l|}{ Smoking } \\
\hline Yes & 3 & $42.9 \%$ & 0.194 & Fisher \\
\hline No & 22 & $21.4 \%$ & & \\
\hline \multicolumn{5}{|l|}{ Physical exercise } \\
\hline Yes & 7 & $19.4 \%$ & 0.547 & $\chi^{2}$ \\
\hline No & 18 & $24.6 \%$ & & \\
\hline \multicolumn{5}{|l|}{ Salt diet } \\
\hline Yes & 10 & $17.2 \%$ & 0.099 & $\chi^{2}$ \\
\hline No & 15 & $29.8 \%$ & & \\
\hline
\end{tabular}

TABLE III - Distribution of sociodemographic and economic variables of Hiperdia users to analyze the association between the variables and adherence to BT

\begin{tabular}{|c|c|c|c|c|}
\hline \multirow{2}{*}{ Variables } & \multicolumn{2}{|c|}{ BATALLA } & \multirow[t]{2}{*}{ p-value } & \multirow[t]{2}{*}{ Test } \\
\hline & Adherence & Non Adherence & & \\
\hline \multicolumn{5}{|l|}{$\overline{\text { Age (years) }}$} \\
\hline Between 20 and 59 & $17(30.4 \%)$ & $39(69.6 \%)$ & 0.8 & $\chi^{2}$ \\
\hline$\geq 60$ & $16(32.7 \%)$ & $33(87.3 \%)$ & & \\
\hline \multicolumn{5}{|l|}{ Gender } \\
\hline Masculine & $8(30.8 \%)$ & $18(69.2 \%)$ & 0.933 & $\chi^{2}$ \\
\hline Feminine & $25(31.6 \%)$ & $54(68.4 \%)$ & & \\
\hline \multicolumn{5}{|l|}{ Occupation/Profession } \\
\hline Farmer & - & - & - & - \\
\hline Housewife & - & - & & \\
\hline Other & - & - & & \\
\hline \multicolumn{5}{|l|}{ Retired } \\
\hline Yes & $19(33.9 \%)$ & $37(38.4 \%)$ & 0.555 & $\chi^{2}$ \\
\hline No & $14(28.6 \%)$ & $35(71.4 \%)$ & & \\
\hline \multicolumn{5}{|c|}{ Monthly household income (n. minimum wages) } \\
\hline Less than 1 minimum wage & $4(36.4 \%)$ & $7(63.6)$ & 0.908 & Fisher \\
\hline Between 1 and 3 minimum wages & $28(31.5 \%)$ & $61(68.5 \%)$ & & \\
\hline More than 3 minimum wages & $1(20 \%)$ & $4(80 \%)$ & & \\
\hline
\end{tabular}


TABLE III - Distribution of sociodemographic and economic variables of Hiperdia users to analyze the association between the variables and adherence to BT (cont.)

\begin{tabular}{|c|c|c|c|c|}
\hline \multirow{2}{*}{ Variables } & \multicolumn{2}{|c|}{ BATALLA } & \multirow[t]{2}{*}{ p-value } & \multirow[t]{2}{*}{ Test } \\
\hline & Adherence & Non Adherence & & \\
\hline \multicolumn{5}{|l|}{ Education } \\
\hline Incomplete primary education & $22(40 \%)$ & $33(60 \%)$ & 0.08 & Fisher \\
\hline Complete primary education & $8(28.6 \%)$ & $20(71.4 \%)$ & & \\
\hline Incomplete high school & 0 & $9(100 \%)$ & & \\
\hline Complete high school & $3(23.1 \%)$ & $10(76.9 \%)$ & & \\
\hline \multicolumn{5}{|l|}{ Marital Status } \\
\hline Single & $7(46.7 \%)$ & $8(53.3 \%)$ & 0.238 & Fisher \\
\hline Married & $24(33.8 \%)$ & $47(66.2 \%)$ & & \\
\hline Widower & $1(9.1 \%)$ & $10(90.9 \%)$ & & \\
\hline Divorced/Separated & $1(16.7 \%)$ & $5(83.3 \%)$ & & \\
\hline Other & 0 & $2(100 \%)$ & & \\
\hline \multicolumn{5}{|l|}{ Number of persons residing in the house } \\
\hline $1(1)$ & $1(16.7 \%)$ & $5(83.3 \%)$ & 0.229 & Fisher \\
\hline 2 to $3(2)$ & $14(26.4 \%)$ & $39(73.6 \%)$ & & \\
\hline 4 to $5(3)$ & $17(43.6 \%)$ & $22(56.4 \%)$ & & \\
\hline 6 to $8(4)$ & $1(14.3 \%)$ & $6(85.7 \%)$ & & \\
\hline \multicolumn{5}{|l|}{ Non-communicable chronic diseases } \\
\hline Hypertension & $29(35.8 \%)$ & $52(64.2 \%)$ & 0.255 & Fisher \\
\hline Diabetes Mellitus & 0 & $4(100 \%)$ & & \\
\hline Hypertension and Diabetes Mellitus & $4(20 \%)$ & $16(80 \%)$ & & \\
\hline \multicolumn{5}{|l|}{ Heredity } \\
\hline Yes & $16(25.8 \%)$ & $46(74.2 \%)$ & 0.199 & $\chi^{2}$ \\
\hline No & $17(39.5 \%)$ & $26(60.5 \%)$ & & \\
\hline \multicolumn{5}{|l|}{ Alcoholism } \\
\hline Yes & $3(27.3 \%)$ & $8(72.7 \%)$ & 0.526 & Fisher \\
\hline No & $30(31.9 \%)$ & $64(68.1 \%)$ & & \\
\hline \multicolumn{5}{|l|}{ Smoking } \\
\hline Yes & $2(28.6 \%)$ & $5(71.4 \%)$ & 0.616 & Fisher \\
\hline No & $31(31.6 \%)$ & $67(68.4 \%)$ & & \\
\hline \multicolumn{5}{|l|}{ Physical exercise } \\
\hline Yes & $15(41.7 \%)$ & $21(58.3 \%)$ & 0.103 & $\chi^{2}$ \\
\hline No & $18(26.1 \%)$ & $51(73.9 \%)$ & & \\
\hline \multicolumn{5}{|l|}{ Salt diet } \\
\hline Yes & $24(41.4 \%)$ & $34(58.6 \%)$ & 0.01 & $\mathrm{X} 2$ \\
\hline No & $9(19.1 \%)$ & $38(80.9 \%)$ & & \\
\hline
\end{tabular}

Hiperdia program has a high dependence on the National Health System (Health Unic System - HUS) and exhibits high social vulnerability.

The mere $55.2 \%$ of patients who adopt a diet lacking in salt is worrisome, because patients suffering from hypertension and/or DM require a high level of compliance in relation to this recommendation.

According to the MGT, the adherence results of only $24 \%$ of patients demonstrated a low level of pharmacological treatment adherence, taking into consideration that the recommended percentage is at least
$80 \%$, according to Carvalho et al. (2012). Similar results were found by Eid et al. (2013), in which a predominance of non-adherence to treatment was observed.

Taking into consideration the proposal of Medeiros (2006) for the MGT, a prevalence of patients classified as the medium adherence group was identified. As such, a greater individual analysis of the four components of the MGT is necessary, with the purpose of observing the influence of each factor for adherence.

Through the analysis of Figure 2, it is clear that, for MGT, the main factors that negatively contributed to 
poor adherence were unintentional characteristics, such as forgetfulness and carelessness in taking medication, corroborating with other studies (Carvalho et al., 2012; Dunbar-Jacob, Mortimer-Stephens, 2001; Kane et al., 2003; Sewitch et al., 2003) in which these behaviors were often responsible for the low level of compliance. According to Morisky, Green, and Levine (1986), these factors are resolve when compared to intentional attitudes.

The analysis of Cronbach's alpha (0.69) to MGT provides a reliability test of the results obtained, giving greater relevance and robustness to the research.

For the BT, $68.6 \%$ of the participants were adherent, demonstrating that they possess a considerable of knowledge about their disease. Inconsistent results for the BT have been found in a study by Carvalho et al. (2012), in which a prevalence of non-adherence among Hiperdia patients was observed. Regarding the BT, the value of Cronbach's alpha of 0.80 reveals a high level of reliability.

By confronting the adherence rates found in this study to the MGT and BT, we identified a large discrepancy, with a prevalence of non-adherence of $76 \%$ for MGT, while in BT there was an adherence predominance of $68.6 \%$. This variation in results between tests can be explained by their different approach to evaluating adherence. In the MGT, the attitudes of the individuals facing the administration of medicines are examined, while the BT observes the participants' knowledge about their illnesses.

This study noted that patients who have DM $(n=24)$ present a discrete increase in rates of adherence to drug treatment for the MGT and BT. This can be explained due to complications of DM being usually more severe and noticeable when compared to the evolution of the hypertension, which often remains silent. With respect to the BT, diabetic patients showed a high adherence $(87 \%)$. However, for the MGT, a low adherence $(39.1 \%)$ was identified. Therefore, regardless of the type of chronic disease, this study noted a discrepancy in relation to the adherence of patients in both tests, with a predominance of non-adherence in the MGT and a prevalence of adherence in the BT.

The study shows the big challenge of hypertension and DM control, predominantly in elderly patients. Given the multifactorial and complex character of these chronic diseases, it is necessary to think about solutions to the difficulties reported by respondents and to intensify actions to strengthen and educate the carrier population and promote the importance of treatment adherence and changes in lifestyle.

\section{CONCLUSION}

The evaluation and conscientization of chronic disease carriers must evolve, aiming at a greater adherence to both prescribed pharmacological and nonpharmacological treatments. In addition, further studies are needed with other methods that better characterize the factors that are contributing to the low adhesion. The multi-professional team of the family health strategy needs to improve its actions and collective programs seeking the excellence in the services rendered, guaranteeing an improved individual assistance.

\section{ACKNOWLEDGEMENTS}

The authors would like to thank the State University of Paraíba, the secretary of health of the municipality of Campina Grande-PB and to the Tutorial Education Program (PET-Pharmacy) of Ministry of EducationBrazil.

\section{REFERENCES}

Assis MMA, Villa TCS, Nascimento MAA. Access to health services: a possibility to be built in practice. Ciênc Saúde Colet. 2003;8(3):815-823.

Barros ACM, Rocha MB, Helena ETS. Treatment adherence and satisfaction with the service among people with diabetes mellitus treated at PSF in Blumenau. ACM Arq Catarin Med. 2008;37(1):54-62.

Busnello RG, Melchior R, Faccin C, Vettori D, Petter J, Moreira LB, Fuchs FD. Associated features to abandonment monitoring hypertensive patients Served in a reference outpatient clinic. Arq Bras Cardiol. 2001;76:349-351.

Carvalho ALM, Leopoldino RWD, Silva JEG, Cunha CP. Adherence to drug treatment in registered users in Hiperdia Program in the city of Teresina - PI. Ciênc Saúde Colet. 2012;17:1885-92.

Carvalho Filha FSS, Nogueira LT, Viana LMM. Hiperdia: Accession and Perception of members Accompanied by the Family Health Strategy. Rev Rene. 2011;12:930-36.

Dewulf NLS, Monteiro RA, Passos ADC, Vieira EM, Troncon LEA. Compliance to drug therapy in patients with chronic gastrointestinal diseases accompanied in outpatients from a university hospital. Braz J Pharm Sci. 2006;42:575-584. 
Dunbar-JacoB J, Mortimer-Stephens MK. Treatment adherence in chronic disease. J Clin Epidemiol. 2001;54(Suppl 1):57-60.

Eid LM, Nogueira MS, Veiga EV, Cesarino EJ, Alves LMM. Adherence to antihypertensive treatment: analysis by MoriskyGreen Test. Rev Eletrônica Enf. 2013;15(2):362-7.

Figueiredo RM, Sinkoc VM, Tomazim CC, Gallani MCBJ, Colombrini MRC. Adherence of AIDS patients to treatment with antiretroviral: difficulties reported and suggestions of measures in a hospital school. Rev Latinoam Enferm. 2001;9:50-55.

Girotto E. Adherence to antihypertensive treatment and factors associated with the coverage area of a family health unit, Londrina, PR. [dissertation] Paraná: State University of Londrina. 2008.

Kane SV, Huo D, Aikens J, Hanauer S. Medication non adherence and the outcomes of patients with quiescent ulcerative colitis. Am J Med. 2003;114(1):39-43.

Medeiros ARC. Adherence to antihypertensive treatment in Health Unit Family of João Pessoa-PB. [dissertation] Paraiba: School of Nursing, Federal University of Paraíba. 2006.

Ministry of Health of Brazil. Hypertension for the Health System. Brasília: Ministry of Health. 2006; 58p.
Ministry of Health of Brazil. Reorganization Plan of Care for Arterial Hypertension and Diabetes Mellitus. Brasilia: Ministry of Health. 2001; 102p.

Morisky DE, Green LW, Levine DM. Concurrent and predictive validity of a self-reported measure of medication adherence. Med Care. 1986;24(1):67-74.

Sewitch MJ, Abrahamowicz M, Barkun A, Bitton A, Wild GE, Cohen A, et al. Patient nonadherence to medication in inflammatory Bowel disease. Am J Gastroenterol. 2003;98(7):1535-1544.

Streiner DL. Being inconsistent about consistency: when coefficient alpha does and doesn't matter. J Pers Assess. 2003;80(3):217-222.

Strelec MAAM, Pierin AMG, Mion JD. The influence of knowledge about the disease and the attitude towards the taking of drugs to control blood pressure. Arq Bras Cardiol 2003;81(4):343-48.

World Health Organization. World health statistics. Geneva: WHO; 2012.

Received for publication on $28^{\text {th }}$ April 2018 Accepted for publication on $23^{\text {rd }}$ August 2018 